\title{
Carbon Dioxide Recovery Skid
}

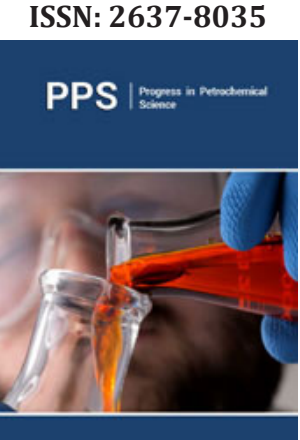

*Corresponding author: Kamil Stasiak, Gdańsk University of Technology, Poland

Submission: 酒 October 05, 2020

Published: 雷 October 23, 2020

Volume 3 - Issue 4

How to cite this article: Kamil Stasiak Paweł Ziółkowski, Dariusz Mikielewicz. Carbon Dioxide Recovery Skid. Progress Petrochem Sci. 3(4). PPS. 000570. 2020. DOI: 10.31031/PPS.2020.03.000570

Copyright@ Kamil Stasiak, This article is distributed under the terms of the Creative Commons Attribution 4.0 International License, which permits unrestricted use and redistribution provided that the original author and source are credited.

\author{
Kamil Stasiak*, Paweł Ziółkowski and Dariusz Mikielewicz \\ Gdańsk University of Technology, Poland
}

\section{Abstract}

"In the face of tightening climate regulations, the adoption of carbon dioxide recovery systems is inevitable. Modular process skid units have been widely adopted across the industry. The gas-steam power plant skid unit with the carbon dioxide recovery system was described. The proposed skid module consists of the compact cycle with the oxy-combustion and the carbon dioxide capture skid unit producing pure compressed C02. The compactness of the suggested skid can be achieved due to a novel small size designs of the wet combustion chamber and the spray-ejector condenser."

\section{Opinion}

Nowadays more and more plants walk away from building various process systems on-site and rely on suppliers for ready to connect modules. Suppliers who are usually the manufacturers (or a proxy between a manufacturer and a contractor) deliver these process systems that are built under off-site conditions. As a result of that, modular constructions have been adopted for ease of handling in commercial use. Such a mobile construction of a process system is called "skid" in English or "anlage" in German. Skids are usually built within a frame. Depending on the dimension of a skid and logistical planning, it can fit, for example, on the back of a truck or in the shipping container [1,2].

Most factories emit a certain volume of carbon dioxide $\left(\mathrm{CO}_{2}\right)$. For example power plants, oil rigs, refineries, waste incinerators, sewage treatment plants, etc. Recent climate restrictions imposed a reduction of $\mathrm{CO}_{2}$ emissions to the environment. As result, a feasible way to capture the $\mathrm{CO}_{2}$ was searched. Depending on the costs and size of a plant, some have decided to build $\mathrm{CO}_{2}$ capture systems onsite, while others (usually smaller) have made decision to pay emission fees. $\mathrm{CO}_{2}$ capture systems built onsite are usually large and may cause additional operational problems. Currently, another rare possibility is to add a compact $\mathrm{CO}_{2}$ capture skid, that solution can benefit both medium and smaller factories. Demand for building reliable systems in the market caused skid manufacturers to build dedicated $\mathrm{CO}_{2}$ recovery systems. Before delivery to a plant, a commercial $\mathrm{CO}_{2}$ skid should be factory acceptance tested (FAT) and certified for its operational use on a manufacturer site, which is an advantage in comparison to these built on plant site without a guarantee [2].

An example of a compact module including $\mathrm{CO}_{2}$ capture process is presented in articles $[1,3,4]$. The proposed power plant module is composed of a gas-steam cycle (with $\mathrm{CO}_{2}$ separation) coupled to a $\mathrm{CO}_{2}$ capture system as shown in Figure 1. The compactness of the proposed gas-steam power plant skid is achieved due to a novel small size designs of the water combustion chamber (WCC) and the spray-ejector condenser (SEC), both based on enhancements of the energy conversion. Conventionally, the size of a combustion chamber and a condenser would be about 30-fold and 32-fold greater than the WCC and the SEC, respectively.

Starting with the WCC in the gas-steam cycle part, the oxy-combustion process takes place, where supplied methane is burnt in the presence of clean oxygen supplied from the ASU through the compressor $\mathrm{C}_{02}$. The ASU separates the high-purity oxygen from atmospheric air basing on the cryogenic method. The waste gas from the ASU is then directed to the $\mathrm{GT}_{\mathrm{N} 2}$ expander which is connected to the main shaft. Due to a high temperature of the oxycombustion in the WCC, the chamber walls are refrigerated by the water injection. Injected water acting as an inert medium, evaporates at the nano level to the combustion chamber. 
The working fluid exiting the WCC, which consists of $10-20 \% \mathrm{CO}_{2}$ vapor and $80-90 \%$ steam is directed to expand in the vapor turbine GT and the vacuum vapor turbine GT ${ }^{\text {bap }}$. In the literature there is also the name of the gas-steam turbine in relation to the vapor turbine (GT $\left.+G^{\text {bap }}\right)[1,3,4]$. Both turbines are connected to the main shaft with the generator $G$, the oxygen compressor $C_{02}$ and the expander $\mathrm{GT}_{\mathrm{N} 2}$. The exhaust vapor leaving the $\mathrm{GT}^{\text {bap }}$ is directed to the SEC after cooling in the regenerative heat exchanger HE. The vacuum in the SEC is generated in the result of properly sprayed nano-droplets of water through the nozzle longitudinally to the main jet, while the working fluid is sucked perpendicularly to the main jet and then immediately mixed in the path of sprayed water. In the main jet, the steam fraction is partially condensed and $\mathrm{CO}_{2}$ compressed simultaneously. The mixture of water steam, liquid water, and compressed $\mathrm{CO}_{2}$ leaves the SEC and raises its pressure to 1 bar entering the condensate-cooler exchanger with the separator $\mathrm{CHE}+\mathrm{S}$. In the $\mathrm{CHE}+\mathrm{S}$ liquid water is cooled, while the remaining mixture of steam water and $\mathrm{CO}_{2}$ is separated in the result of the main jet action in the SEC. Some of cooled water exiting $\mathrm{CHE}+\mathrm{S}$ is pumped back to the SEC spraying nozzle. The rest of water is pumped back to the WCC after being preheated in the HE, while an excess of water is being removed (which is produced during combustion) [1,3,4].

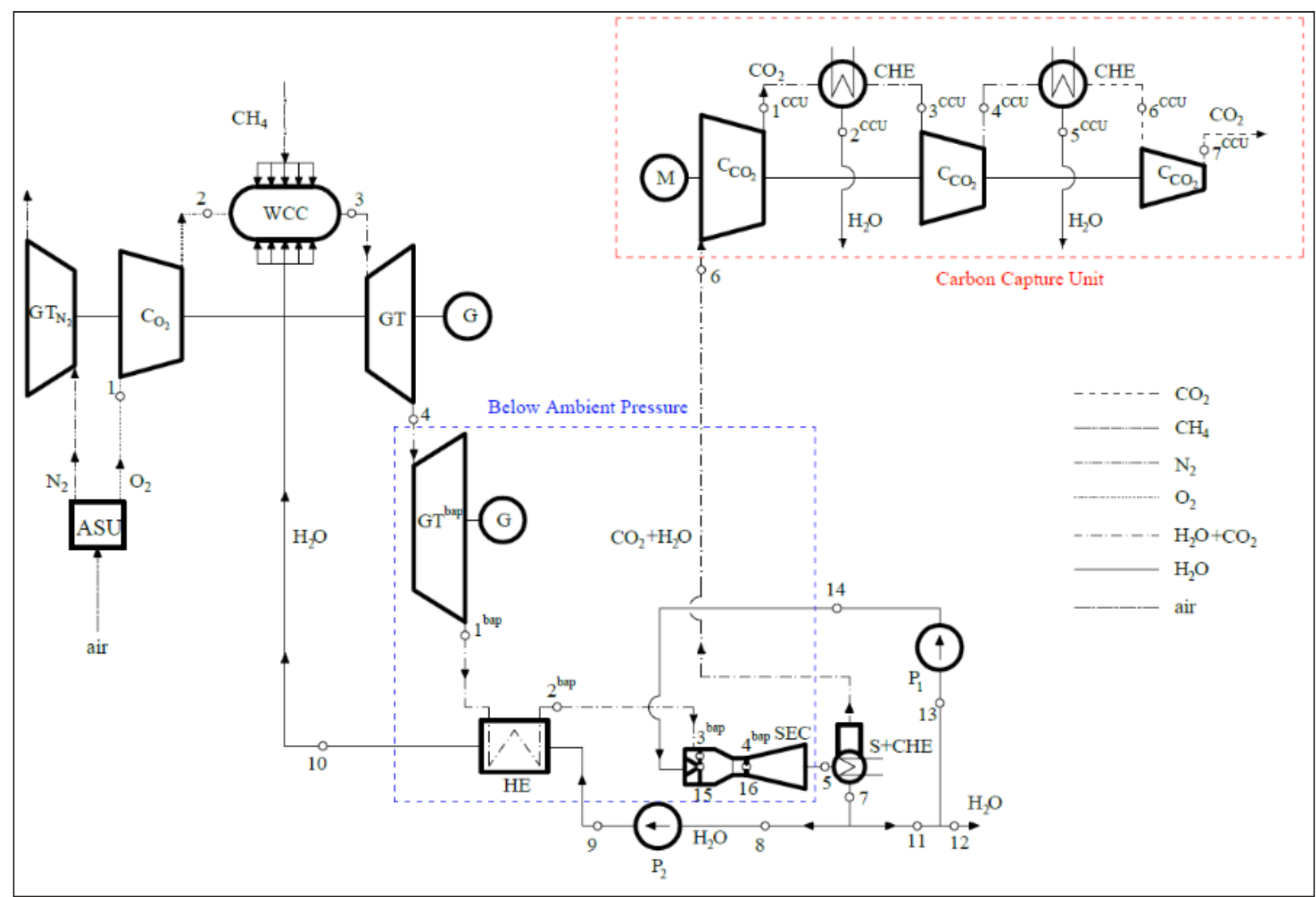

Figure 1: The compact cycle with oxy-combustion and $\mathrm{CO}_{2}$ capture, where WCC - wet combustion chamber, $\mathrm{GT}+\mathrm{GT}^{\text {bap }}$ - vapor turbine divided into two parts, SEC - spray ejector condenser, ASU - air separation unit, $\mathrm{C}_{\mathrm{O} 2}$ - compressor, $\mathrm{HE}$ - regenerative heat exchanger, $\mathrm{CHE}+\mathrm{S}$ - condensate-cooler heat exchanger and separator, $\mathrm{CHE}$ - cooling heat exchanger, $\mathrm{M}$ - motor, $\mathrm{G}$ - generator, $\mathrm{P}_{1}$ - supply water pump, $\mathrm{P}_{2}$ - water pump for cooling combustion chamber, $\mathrm{GT}_{\mathrm{N} 2}-$ expander $\mathrm{N}_{2}, \mathrm{C}_{\mathrm{CO} 2}-\mathrm{CO}_{2}$ compressor.

In the $\mathrm{CO}_{2}$ recovery part, the mixture of compressed $\mathrm{CO}_{2}$ and steam from the CHE+S separator from the gas-steam cycle skid is directed to series of $\mathrm{CO}_{2}$ compressors $\mathrm{C}_{\mathrm{CO} 2}$ powered by a motor, between compressors water is condensed from the steam in the cooling heat exchangers CHE. As the result, clean compressed $\mathrm{CO}_{2}$ is produced from the outlet of the $\mathrm{CO}_{2}$ recovery skid.

In conclusion, the feasible way to capture $\mathrm{CO}_{2}$ was presented within the compact build of power plant skid. Wide commercial application of such skids including $\mathrm{CO}_{2}$ capture is the matter of certain factors, like the cost of a $\mathrm{CO}_{2}$ capture skid unit, the climate regulations, the $\mathrm{CO}_{2}$ emission fees, and the size of a plant. While the cost of manufacturing of a compact $\mathrm{CO}_{2}$ uptake skid will possibly reduce, both the $\mathrm{CO}_{2}$ fees are likely to be increased and the climate regulations be tightened with time. It can be assumed that the balance of these factors will shift toward the cost-effective application of $\mathrm{CO}_{2}$ reuptake skid units. Especially smaller factories would benefit from this. From the technical view, the development progress of viable $\mathrm{CO}_{2}$ capture skids is demanded to be done to maintain this trend. 


\section{Acknowledgments}

This article has been prepared within the frame of the project "Negative $\mathrm{CO}_{2}$ emission gas power plant" - NOR/POLNORCCS/ NEGATIVE-CO2-PP/0009/2019 the project is co-financed by POLNOR 2019 under the Norwegian Financial Mechanism 20142021.

\section{References}

1. Ziółkowski P (2018) A thermodynamic analysis of a gas-steam turbine incorporating a full model of a spray-ejector condenser. Trans IFFM 139: 63-96.

2. Pentair PLC (2016) A compact enclosed skid $\mathrm{CO}_{2}$ recovery system for biogas upgraders, Italy.
3. Ziółkowski P, Badur J, Kruczek HP, Nedźwiecki Ł, Kowal M, et al. (2019) A novel concept of negative $\mathrm{CO}_{2}$ emission power plant, based on combustion the gas from sewage sludge gasification in a gas turbine with spray-ejector condenser. XXIV International Symposium on Combustion Processes, Australia, pp. 144-145.

4. Ziółkowski P, Badur J (2019) A study of a compact high-efficiency zero-emission power plant with oxy-fuel combustion. In: Stanek W, Gładysz P, Werle S, Adamczyk W (Eds.), ECOS, Proceedings of the $32^{\text {nd }}$ International Conference on Efficiency, Cost, Optimization, Simulation and Environmental Impact of Energy Systems, Wroclaw, Poland, pp. 1557-1568. 